\title{
Anverso y reverso de la nación: el discurso de la antiespañolada du- rante los primeros años $40^{*}$
}

\author{
Zira Box Varela \\ Universitat de València
}

RESUMEN: Durante los años de la inmediata posguerra, diferentes voces del nuevo régimen franquista elaboraron un discurso relativamente espontáneo pero, a la par, suficientemente reconocible, dirigido a denunciar lo que consideraban como intolerables deformaciones de lo español. Básicamente, y a pesar de las diferencias ideológicas de sus productores, la crítica nacía de un común y doliente nacionalismo que señalaba con el dedo acusatorio a la mirada extranjera - especialmente, a la de los románticos franceses del siglo XIX-como creadores y sostenedores de lo que suscribían como una España de pandereta. Dicha imagen suponía una distorsión y mixtificación de la patria en su pintoresquismo que, desembocando en lo que calificaban de españolada, se hacía urgente corregir. La intención de este artículo es explorar el mencionado discurso, denominado en el texto como de antiespañolada, a partir de la hipótesis de que la actitud de estos críticos no implicó una eliminación de los tópicos con los que se había formado el equívoco reflejo, sino su restitución y resignificación. Así, elementos aparentemente tan tipistas como los toros, el flamenco o Andalucía se reivindicaron como típicamente españoles, pero de una España que, lejos de responder a las estridencias de la españolada, se presentaba como una nación seria, recta y jerárquica.

PALABRAS CLAVE: españolada; primer franquismo; toros; flamenco; nacionalismo franquista; problema de España.

* Una versión de este texto fue discutida en el Seminario de Historia Contemporánea del Instituto Universitario Ortega y Gasset. Agradezco a Edward Baker, su comentarista y a todos los asistentes sus sugerencias. La autora participa en los proyectos HAR2011-27392 y HAR2012-37963-C02-01. 
Obverse and reverse of the nation: the discourse of the antiespañolada during the early Forties.

ABSTRACT: During the immediate postwar years, different voices from the new francoist regime produced a discourse relatively spontaneous but, at the same time, recognizable enough addressed to denounce what they considered as an unacceptable deformation of the Spanishness. Basically, and in spite of the ideological differences amongst its producers, the critic raised from a common and painful nationalism which pointed at the foreign look - specially, the French romantic look- as creator and supporter of what they called España de pandereta. This look supposed a distortion and mystification of Spain as a picturesque nation that resulted in the españolada. The aim of this article is to explore this discourse - named in the text as the antiespañolada discourse-proposing a hypothesis: these critics did not expect to eliminate the clichés linked to this image, but to restore them giving to them a new signification. Consequently, elements as typical as bullfighting, flamenco or Andalusia were claimed as deeply Spanish elements, but representatives of a Nation that far from being coloured with the stridency of the españolada was a hierarchy, serious and a straight Nation.

KEY WORDS: españolada; early Francoism; bullfighting; flamenco; francoist nationalism; problem of Spain.

En 1953, el Ministerio de Información y Turismo, creado apenas dos años antes, convocó un concurso de ideas para elaborar la publicidad adecuada de cara a expandir el fenómeno turístico en España. La iniciativa consistía en buscar la imagen que se podía exportar con el fin de atraer a los futuros visitantes. La mayor parte de los participantes insistieron en que la principal baza que podía jugar el país era acentuar su diferencia. Así lo había señalado un promotor holandés al concluir que el folklore, los toros y el sol parecían seducir más a los extranjeros que a los propios españoles, y así lo resaltaba, también, una de las propuestas presentadas en el concurso elaborada por un experto funcionario de la Dirección General de Turismo: era indudable que el viajero que llegaba a España buscaba comodidades y facilidad, buena comida y mejor vino. Pero era indudable, igualmente, que el viajero buscaba lo pintoresco, esto es, españoladas: toros, baile, flamenco, cante, gitanos y ciudades andaluzas: Sevilla, Córdoba y Granada. «Hemos de resignarnos turísticamente a ser - concluía el concursante - un país de pandereta, puesto que el día que perdamos la pandereta habremos perdido el noventa por ciento de nuestros motivos de atracción turística» ${ }^{1}$. La historia que viene después es conocida: el Spain is different se convirtió en el eslogan oficial del Ministerio a par-

1 Citado en PACK, 2009: 116-117. 
tir de 1957 y la imagen de España en el exterior pareció retroceder más de cien años en el tiempo, cuando los primeros viajeros románticos llegaban al país ávidos de encontrar ese mismo exotismo que, a punto de entrar ya en los desarrollistas años 60, comenzaba a exportarse de forma oficial ${ }^{2}$.

El objetivo de este artículo implica viajar de nuevo hacia el pasado. En concreto, una década y media atrás con respecto al boom turístico en España y, por ende, a la revitalización de la españolada asociada con él. Porque, antes de que el tipismo adquiriera estatus oficial y de que la imagen española incidiese principalmente en su pintoresca diferencialidad, se desarrolló dentro de la naciente dictadura un discurso fuertemente nacionalista encaminado, precisamente, a denunciar las que se consideraban intolerables deformaciones de lo español. Los actores que alzaron sus voces y sus plumas fueron diversos: pertenecieron a los diferentes sectores ideológicos del régimen. Y lo hicieron, a su vez, con niveles divergentes de belicosidad. Unos, como los falangistas radicales de la inmediata posguerra, lo hicieron con vehemencia y acusación; otros, algo más tibios, con carácter resignadamente informativo destinado a intentar corregir el error; unos y otros, en cualquier caso, compartieron el mismo ímpetu nacido de una entraña ultranacionalista dirigida a probar la distorsionadora mirada extranjera que, desde las primeras décadas del siglo XIX, había convertido al país en una nación de excesos y pintoresquis$\operatorname{mos}^{3}$. Probablemente, muchos de quienes coincidieron en la elaboración de este discurso que podríamos denominar como de antiespañolada, difícilmente se habrían puesto de acuerdo en cómo habría de ser políticamente la nación que defendían ${ }^{4}$. Sin embargo, para el argumento que aquí interesa, esta cuestión tiene escasa importancia. Porque, por muy diferente que fuese la España soñada como nacionalsindicalista durante los primeros meses de posguerra, de la España tradicionalista, católica y conservadora auspiciada por los sectores pertenecientes a la derecha contrarrevolucionaria, todos ellos defendieron una nación recta, austera, seria y jerárquica. Una España, en definitiva, plenamente alejada de aquella otra marcadamente colorista y folklorista propia

2 Una visión de conjunto, en STORM, 2013.

3 La importancia de «la mirada del otro» en la construcción de las identidades nacionales ha sido señalada en diferentes trabajos. Cabe apuntar SAZ, 31 (Madrid, 1998). La complejidad implícita en dicho proceso, analizando la (re)negociación con la imagen externa, así como la dialéctica rechazo-asunción, en ANDREU, 2009. Igualmente, ÁLVAREZ BARRIENTOS, 2001: 21-36. MARCO, 1987: 125-140.

4 Se utiliza la idea de «antiespañolada» en función de que los actores con los que se trabaja utilizaron el término de españolada para referirse a la imagen de España distorsionada y exagerada en su pintoresquismo, originada a partir del romanticismo francés, a la que se oponían. Dicha definición coincide con la que se puede encontrar en el diccionario de la RAE, que define españolada como «acción, espectáculo u obra literaria que exagera el carácter español». 
de la romántica españolada. El propósito de este artículo es, precisamente, explorar este discurso, escasamente estudiado hasta el momento y, sin embargo, suficientemente significativo a nuestro juicio. Porque, a pesar de que, ciertamente, no se trató de un discurso generalizado ni sistematizado, sí parece posible rastrear toda una serie de heterogéneas voces críticas que, durante los mismos años, y esgrimiendo argumentos más o menos similares procedentes de un profundo y doliente nacionalismo, se opusieron a lo que se interpretaba como una humillante falsificación de la nación.

\section{ANVERSO Y REVERSO DE LA NACIÓN: LA RESTITUCIÓN DE LOS TÓPICOS}

En 1902, se publicó en la editorial de la Revue Blanche de París la novela La Marquesita. Roman de moeurs espagnoles, escrita por Jean-Louis Talon. El libro - cuyo subtítulo era plenamente explicativo de las intenciones que contenía - carecía, como cabría esperar, de cualquier atisbo de originalidad. Situada en el Madrid de finales del siglo XIX, el argumento giraba en torno a los amores del torero sevillano Manolo Bocanegra con la inocente Soledad, apodada la marquesita, en una historia salpicada de tabernas, casas de huéspedes, ruedos y comidillas varias de la capital. Los ingredientes del plato eran los mismos que la cocina romántica extranjera - especialmente, la francesa, aunque no solo - había cocinado con dedicación a lo largo de las décadas previas a la publicación del libro: a pesar de las ambigüedades provocadas por un país tan fascinante como decadente, peligroso $\mathrm{y}$, hasta por momentos, atroz, la visión foránea sobre España había insistido en el exotismo de una nación de toreros, bandoleros o gitanos atravesados por sentimientos encontrados plenos de pasiones, celos y desproporciones; los mismos que, en este caso, habían invadido, en una dramática secuencia final para llevarla hasta la muerte, a la protagonista Soledad ${ }^{5}$. La marquesita no era, por tanto, ni un texto original, ni mucho menos una obra destacada dentro del género; más bien al contrario, se trataba de una secundona tardía y casi desconocida que le servía, sin embargo, al periodista y escritor Melchor Almagro San Martín, para ejemplificar desde Vértice las exageraciones y tópicas incongruencias de la españolada, aquel espejo cóncavo deformante que en la novela de Talon alcanzaba «todo su auge disparatado y pintoresco», según el parecer de Almagro.

«La españolada del tono gabacho muy 1850», continuaba el citado artículo, suponía «figuras femeninas de peineta y pañolón de manila, toreros de opereta cómica, contrabandistas y bandidos de trabuco». Porque el sol español $\mathrm{y}$, principalmente, el andaluz, tenía necesariamente que cegar la vista a

5 La visión de los románticos franceses sobre España, en AYMES, 1983. Una visión de los viajeros ingleses, en ROBERTSON, 1998. Una visión de conjunto, en SERRANO, 1998. 
quienes acostumbrados a contemplar diariamente los suaves paisajes de la isla de Francia veían el mundo velados por las grises neblinas. «Por eso, fondos y personajes hispánicos surgen en las páginas allende el Pirineo con tonos exuberantes o exasperados». No obstante, reconocía Almagro San Martín, pudiera ser que estas descripciones estuvieran basadas en una cierta realidad. Sin embargo, a los españoles no podían dejar de resultarles mentirosas alteraciones del carácter español, unas distorsiones que había que combatir6.

La citada llamada de atención que Melchor Almagro lanzaba desde Vértice situaba la cuestión en el punto exacto del debate. No iba a ser, además, una crítica aislada, sino que se iba a sumar a otras tantas destinadas a incidir, durante los primeros años de posguerra, en la misma idea: avisar de esa España pintoresca y torcida, como la denominaría Rafael Sánchez Mazas en un discurso de los primeros días de victoria ${ }^{7}$. En esta queja ante los excesos y desproporciones de la España típica y tipista, los vencedores utilizaron elementos previamente conocidos en la reciente historia intelectual del país: especialmente visible en el sector falangista de aquellos años, lo que, en última instancia, se expresaba a través de este tipo de discurso era el dolor por la diferencialidad y por el alejamiento y la anormalidad del país con respecto a la modernidad; el descontento ante el hecho de que la mirada foránea oportunamente ayudada por tantos españoles que habían asumido y contribuido a mantener el tópico - insistiera en el exotismo junto a todos aquellos elementos que desviaban a España de la norma europea. En definitiva, el pesar ante esa simplificadora y estereotipada imagen que orientalizaba y mixtificaba al país desde una conciencia de superioridad albergada por las potencias europeas $^{8}$. Lo advertía con total claridad Antonio Tovar en El imperio de España, recordando que los enemigos de hoy eran los mismos que los de ayer, aquellos que «después de vernos caídos, después de habernos aniquilado como potencia mundial y habernos hecho perder dimensiones de Imperio, y después de quitarnos a fuerza de fatiga nuestra tensión y nuestra voluntad, nuestra fe en los destinos de España, nos tienden la mano falsa de la curiosidad turística». Sobraban en el mundo hispanistas que mirasen a España como a una «nación muerta y llena de curiosidades». Falange no tenía miedo a los enemigos abiertos, a todos los que hiciesen tomar al país actitudes de guerra para mantenerles en el jaque

6 ALMAGRO SAN MARTÍN, 1941.

7 La expresión de España de pandereta tiene su origen en Antonio Machado (España, país de charanga y pandereta). El discurso de Sánchez Mazas, en «Sánchez Mazas ha hablado», Arriba, 9 de abril de 1939.

8 Una visión de conjunto de esta interpretación de España como dolor y anomalía, en JULIÁ, 66 (Madrid, 1996). La construcción ideológica y estereotipada del otro, en respuesta al Orientalismo de Edward Said, en BHABHA, 1994: 66-85. Una aplicación de la teoría de Bhabha y Said al caso español, en LABANYI, 2004. 
salvador del peligro. Pero lo que no se podía consentir era a «esos enemigos que no quieren decirlo y que, a la sombra de hispanismos de cosas muertas, ponen en peligro de muchos sitios del mundo el español vivo» ${ }^{9}$.

Había preocupación y dolor por España, se dijo antes, un dolor que era $n a-$ cional porque, como explicaba otro falangista radical del momento, en este caso, Pedro Laín Entralgo, a esta generación de la inmediata posguerra les dolía el país lo mismo que les había dolido a sus abuelos del 98. "Amamos a España porque no nos gusta», había dicho José Antonio Primo Rivera en una repetida expresión que, en esta ocasión, era reiterada por Laín. Si era indudable que existía un cierto atraso patrio, se hacía más urgente que nunca ser optimistas para sacudirse el polvo, desprenderse de «la fatal incapacidad ante el empeño de entender a España como empresa nacional inmediata, como quehacer español capaz de ilusión, hazaña y provecho» ${ }^{10}$. A este respecto, librarse de los tópicos sobre el atraso patrio cultivados alrededor del recurso al pintoresquismo nacional resultaba fundamental: había que eliminar la españolería bufa a la que tanto habían contribuido extranjeros y locales para esgrimir, a cambio, la otra España, esa que, en términos falangistas, era la exacta y la difícil ${ }^{11}$. Porque el país ya no era, tal y como bramaba el ministro Ramón Serrano Suñer pocas semanas después de concluida la victoria, «un pueblo dormido», «un pueblo extraviado y triste, tejido por el romanticismo a base de deformar la leyenda en la historia». Llegado el nuevo y victorioso momento, España contaba, a cambio, con «una juventud disciplinada pero dispuesta siempre a servir con violencia y ardimiento los destinos y el poderío de la Patria» ${ }^{12}$.

El discurso, se ha advertido, no se circunscribió exclusivamente a Falange, a pesar de que fueron las cabezas del partido las que, en buena medida, salieron a la palestra para denunciar la deformante imagen española. Como se apuntó antes, otras voces públicas pertenecientes a los diversos sectores ideológicos del régimen participaron, también, de esta queja doliente ante el reflejo romántico de la nación y del esfuerzo por corregir la imagen que se reflectaba en ese espejo cóncavo fruto de la españolada, el término que también ellos utilizaron desde su específico pesar ante el problema de España. Se dice, como se ve, corregir y no tanto eliminar porque la idea que se propone aquí

9 TOVAR, 1941: 12-13.

10 LAÍN ENTRALGO, 1943: 39-40.

$11 \mathrm{La}$ expresión pertenece al artículo «España, incómoda», publicado en $\mathrm{Haz}, 26$ de marzo de 1935. Recogido en PRIMO DE RIVERA, 1971: 452.

12 El discurso de Ramón Serrano Suñer en Barcelona se puede ver en la prensa del 15 de junio de 1939. Una visión de conjunto del nacionalismo falangista dentro del cual se pueden contextualizar las ideas expuestas, en SAZ, 2003. La España recta en oposición a la España torcida dentro del nacionalismo falangista, en BOX, 2012. 
es que el discurso nacionalista de la antiespañolada no negó los elementos establecidos desde el siglo anterior como típicamente españoles, sino que se propuso dar la vuelta a la manida descripción para reivindicarlos desde la otra cara reflectante, la cara desde la que se creía mostrar la realidad ajustada a sus correspondientes proporciones. Consecuentemente, y como se verá a continuación, elementos tan aparentemente tipistas como los toros, el flamenco o la misma Andalucía fueron reclamados como esencialmente españoles, como expresiones de un latir propiamente nacional, pero de una nación que estaba - eso sí- en las antípodas de la dañina imagen romántica importada ${ }^{13}$.

\section{Los toros}

El 24 de mayo de 1939, la plaza de toros de Madrid abría sus puertas a los nuevos tiempos de la victoria. Había ganas de toros, escribía el crítico y cronista taurino del diario Arriba, R. Capdevila, pseudónimo utilizado por Celestino Arenal. Ganas de toros, pero no de toros en cualquier sitio, sino de toros en Madrid. Servidos tan oportunamente los acontecimientos en bandeja, Capdevila no se ahorraba tinta a la hora de aludir al discurso sobre la ansiada salvación y redención de la ciudad, ese que insistía en la recuperación de la capital cautiva tras los años republicanos de la guerra. Por fin esa tarde, proseguía el cronista, se había producido la resurrección de los toros, su esperada vuelta pasados ya los tiempos de angustias y dolores, de incertidumbres y novilladas robadas a la lucha en la zona nacional. El espectáculo había sido grandioso ya que, junto al arte de los diestros, lo que se había podido ver en el ruedo había sido la grandeza de la nueva España franquista. Los gritos patrióticos habían brotado de continuo, relataba Capdevila, así como las aclamaciones a los generales presentes, el general Saliquet y el general Varela, y a la aviación que sobrevolaba por encima de la plaza. Entre todos, había destacado un momento por su gran solemnidad: la interpretación a cargo de la banda de los himnos del Triunfo Nacional, como los denominaba Capdevila, y la bóveda de gloria formada por veinticinco mil brazos extendidos entonando, tras el himno nacional, conjuntamente el Cara al Sol ${ }^{14}$.

A partir de ese momento, y a pesar de las destrucciones de ganaderías y de la escasez de pastos y piensos ocasionados por la guerra, hubo toros en Ma-

13 Aunque no es objeto de este trabajo, la reivindicación del flamenco o los toros como propiamente españoles, aunque no de la españolada, formó parte de corrientes ideológicas totalmente contrarias al franquismo. Basta recordar a muchos de los integrantes de la Generación del 27 y algunos de los trabajos artísticos que se promovieron durante la República.

14 ESPINOSA, Celestino, «Toros en España», Arriba, 25 de mayo de 1939. 
drid con su normal asiduidad ${ }^{15}$. Con toros se festejaron fiestas y celebraciones, y con toros se resaltaron, también, acontecimientos políticos, como la visita oficial a la capital del jefe de las SS alemanas, Heinrich Himmler, quien, tras la entrevista mantenida con Franco a finales de octubre de 1940, asistía a la posterior corrida organizada en su honor ${ }^{16}$. La fiesta nacional gozó, por tanto, de salud durante los años de posguerra - no hace falta recordar que la década de los 40 sería la de figuras míticas como Belmonte o Manolete ${ }^{17}$. Sin embargo, el argumento que se quiere señalar aquí es que, durante los primeros años de la dictadura, la fiesta fue objeto de algunas recolocaciones semánticas y discursivas destinadas a resituar el espectáculo taurino en lo que se consideraba su valor exacto. El mencionado movimiento se iba a hacer, además, de forma doble: por un lado, el discurso franquista se esforzó en alejar la fiesta de todo tópico o pintoresquismo propio de la españolada; por otro, y tal y como se anunció al principio, se incidió en el carácter propiamente español de los toros. Pero español no de cualquier forma, sino como algo plenamente representativo de una España valerosa, seria y grave; una España, en definitiva, que estuviese a tono con los solemnes tiempos de la posguerra.

En ello residía la clave, porque entre todas las molestas conclusiones que el tópico romántico había elaborado con eficacia sobre el país, la pasión, la barbarie y el primitivismo asociados al toreo habían sido, tal vez, unas de las más recurrentes ${ }^{18}$. Para los viajeros que llegaban a la Península, el espectáculo taurino constituía una visión inexcusable, como señaló Jean-René Aymes; el momento ineludible en el que el extranjero interrogaba en la arena, so pena de que luego se le reprochase haber desperdiciado el viaje por el país, al alma española ${ }^{19}$. En un momento en el que la propia fiesta nacional comenzaba a profesionalizarse e institucionalizarse, los románticos que cruzaban los Pirineos creían encontrar el espíritu español - ese espíritu fascinante, pero incapacitado para la modernidad - en los ruedos que visitaban ${ }^{20}$. Constituían las corridas, se explicaba también desde Vértice, el motivo central de la españolada, «y si a las descripciones coloristas del festejo» se sabían mezclar «graciosamente por los autores amores bravíos, duquesas majas e hidalgos punti-

15 AMORÓS, 1942. DE URRUTIA, 1974: 100.

16 SHUBERT, 1999: 213. La «politización» de la fiesta no fue exclusiva del momento dictatorial. Para los años republicanos ver CLARAMUNT, 2006. La crónica de la entrevista de Himmler con Franco y de la corrida de toros en su honor se puede ver en la prensa del 22 de octubre de 1940.

17 DE URRUTIA, 1974: 109 y ss.

18 ANDREU, 72/4 (Madrid, 2008): 47.

19 AYMES, 1983: 22.

20 Aunque existieron diversas disposiciones previas, suele considerarse que el punto de partida de la regulación oficial de los diferentes aspectos de la corrida fue el reglamento redactado por el abogado y político Melchor Ordóñez en 1847. 
llos», quedaba «el mejunje literario a punto de caramelo y en guisa de servirlo a los extranjeros golosos de exotismo» ${ }^{21}$. A ello, en efecto, habían dedicado páginas y lírica, desde la fascinación y la curiosidad, los románticos del siglo $\mathrm{XIX}^{22}$. Y a ello dedicaron, también, algunos escritores, intelectuales o periodistas del primer franquismo, no tantas páginas, pero sí un cierto esfuerzo, con la intención de reivindicar que la correcta conclusión de la centuria anterior - aquella que postulaba que el alma española y el espíritu patrio palpitaban en las arenas de las plazas - tenía que ser sustancialmente modificada: este carácter puramente español no consistía en la bárbara visión de los estoques o de las capeas, sino en el valor y el rigor del buen hacer de un torero en lucha a muerte con el animal en el ruedo.

En este punto, el discurso nacional del franquismo se desviaba del camino ya trazado en el que se había parcialmente situado. Porque, como se señaló al principio, en la crítica a la imagen patria importada y en la explícita intención de revocarla había una asunción del sempiterno problema de España. Especialmente visible fue en el caso de Falange, deudora - al menos, en su sector más radical - de la corriente regeneracionista iniciada con la crisis finisecular ${ }^{23}$. Unos y otros habían compartido el afán de zarandear desde la crítica visceral al país, pero unos y otros, también, se habían distanciado a la hora de dirigir el dedo acusatorio hacia el lugar donde creían hallarse las causas de los males de la patria. En el caso de la gran mayoría de los intelectuales del 98 y de algunos de las dos primeras décadas del siglo $\mathrm{XX}-\mathrm{y}$, antes que ellos, entre los reformistas ilustrados y los principales escritores costumbristas del siglo XIX-, la oposición y hostilidad ante la denominada fiesta nacional había sido manifiesta ${ }^{24}$. La moneda común argumentativa había estribado en identificar las penurias nacionales con lo castizo, entendiendo esto último como sinónimo de lo típico y lo popular. Y para aquellos observadores de la situación de España, nada había tan representativo del tipismo español asumido como equivalente del atraso nacional que la crueldad y la desidia implícitas en los toros, gráfica muestra del alejamiento de España de una modernidad ansiada como necesaria ${ }^{25}$. Así se había manifestado en Unamuno, Maeztu, Azorín o Baroja ${ }^{26}$; algo después, y de forma mucho más ambigua, en Ortega y

21 ALMAGRO SAN MARTÍN, 46-47 (Madrid, 1941).

22 BERNAL RODRÍGUEZ, 1987: 116-120. GONZÁLEZ TROYANO, 1988.

23 SAZ, 2003: 246 y ss.

24 ÁlVAREZ SANTALÓ, 1 (Sevilla, 1994): 93-114. ANDREU, 72/4 (Madrid, 2008): 32-35. Para la postura de los escritores costumbristas, JIMÉNEZ MORALES, 6 (Sevilla, 1997): 43-86.

25 Esta argumentación está desarrollada en NÚÑEZ FLORENCIO, 2013.

26 Unamuno, por ejemplo, en su escrito «El deporte tauromáquico», diría que la fiesta estaba entonteciendo al pueblo, pues esta no irradiaba lo más bravío de la patria, sino lo más insustancial y mentecato. En Hacia otra España, Maeztu concluía que, entre las 
Pérez de Ayala ${ }^{27}$. Y de manera especialmente estentórea lo había hecho Eugenio Noel28. En el discurso del primer franquismo que nos interesa, sin embargo, y otra vez de forma especial en el falangista, puede que el objetivo fuera el mismo: criticar a España desde el profundo nacionalismo para corregir sus males y restituirla en su correcta medida. Puede, incluso, que compartiesen - al menos, el falangismo radical - una básica postura fuertemente anticastiza. Sin embargo, en el caso de estos últimos no parecía necesario tirar al niño con el agua sucia, es decir, no parecía forzoso negar elementos como el toreo para defender una idea alternativa de España. Más bien al contrario, se asumía que la fiesta era representativa del carácter español siempre y cuando no hubiese dudas de lo que este significaba.

Que rebanar la nariz entera afeada tan solo por una verruga era, literalmente, una estupidez, lo declaraba desde las páginas de $A B C$ el periodista y escritor José Carlos Luna. Lo hacía en un artículo titulado «El espectáculo más nacional», guiño al erudito libro publicado por el conde las Navas con el inicio del siglo y al que Luna remitía a todos aquellos detractores del toreo, por estimarlo españolada, para que se curasen de espantos y pamplinas. Porque resultaba evidente que «un toreador de faja carmesí, con moño en la cadera, escarpines engalgados, espadín de gavilanes y muleta con morillas» sería siempre «una cosa grotesca, tan lejos de la plaza de toros de Ronda como puedan estarlo el esquimal y el negro de La Martinica» ${ }^{29}$.

Con respecto al hecho de que la plaza de toros pudiera constituir, en efecto, la esencia del carácter patrio, un «tentadero de la esencia española», donde vicios y virtudes nacionales se situaban sin florituras ni concesiones, sino así, a la intemperie, lo corroboraba el director general de Cinematografía, Manuel Augusto García-Viñolas, nuevamente desde Vértice, en concreto, en un número doble publicado en el verano de 1941 dedicado íntegramente al toreo ${ }^{30}$. Los mensajes que se sucedían en los diferentes artículos insistían en la escasez de pintoresquismo folklórico o festivo que suponía la celebración. Alejado de lo anterior, el espectáculo taurino ponía de manifiesto la profundidad del alma española, enraizada en el sentimiento dramático y solemne de la vida

responsabilidades del Desastre, estaba «nuestra desidia, nuestra pereza, el género chico, las corridas de toros, el garbanzo nacional, el suelo que pisamos y el agua que bebemos». Por su parte, Azorín relataba en Castilla que lo que no escribía el poeta acerca de los toros era lo que vendría después: «las reyertas, los encuentros sangrientos entre los mozos, las largas clamorosas borracheras, de vinazo espeso, morado; el sedimento inextinguible que en este poblado de Castilla dejarán estas horas de brutalidad humana».

27 Las ambigüedades de los «novecentistas», en CAMBRIA, 1974: cap. 4.

28 Basta recordar sus obras Flamenquismo y toros. Escritos antitaurinos o Pan y toros. Un análisis de su obra, en CAMBRIA, 1974: cap. 5.

29 DE LUNA, José Carlos, «El espectáculo más nacional», $A B C, 14$ de marzo de 1944.

30 GARCÍA VIÑOLAS, 46-47 (Madrid, 1941). 
entendida como una aventura ${ }^{31}$. Para una concepción de la vida como la falangista, en la que la existencia se concebía como milicia, y para un régimen emergido de una guerra en la que el arrojo se aireaba como una pieza clave de su condición de vencedor, el toro canalizaba la capacidad propia del hombre español para enfrentarse al peligro, la oportunidad que ofrecía el estar solo frente al animal en el ruedo para contemplar - y acaso fuera esto lo más esencial - la lucha del hombre con el mundo exterior. Torear implicaba estar ante el peligro y ser capaz de sortearlo. Poder dominar los elementos para someterlos a la propia voluntad ${ }^{32}$. La pasión inherente a un espectáculo de plazas abarrotadas no se podía negar. Pero la pasión, argumentaba el crítico taurino Federico M. Alcázar, no quitaba, de ninguna manera, entendimiento; tampoco sensibilidad, porque el toreo era una fiesta de sensibilidad y de entendimiento, de pasión y de concepto. Y, sobre todo, era una fiesta de valor, de ese tipo especial de valor que brotaba de ver pelear y triunfar a la vida con la muerte. Consecuentemente, concluía Alcázar, era un arte puro, «despojado de todo artificio» y alejado de la barbarie o del pasional carácter español porque, en este caso, torear significaba el triunfo de la razón sobre los instintos, de la inteligencia sobre la fuerza bruta ${ }^{33}$.

El valor propio de la fiesta era, por tanto, una de las piezas clave del discurso franquista esgrimido con respecto a los toros. Era precisamente el mismo Alcázar quien contaba, desde su dilatada experiencia en la redacción de $E l$ Imparcial y, una vez acabada la guerra, en el diario Madrid, con un buen número de textos en los que la vindicación del valor, concebido este de un modo esencialista - como una semilla que se podía cultivar, pero no crear-y apartado de la temeridad o del instinto, constituía la clave para explicar el arte del toro $^{34}$. En resumen, la fiesta de los toros, nacida «de nuestra tierra y de nuestra sangre», no era, ni mucho menos, lo que «se llama despectivamente la España de pandereta», proseguía, en este caso, de nuevo Melchor Almagro, sino «una España hecha de valor y de luz, de sangre y de trigales», testimonio notable «de nuestra gran alma heroica» ${ }^{35}$.

En lo relativo a los toros, los primeros años de la dictadura fueron, también, los años en los que salieron a la luz algunos libros relevantes al respec-

31 LAFUENTE FERRARI, 46-47 (Madrid, 1941).

32 «Las capeas», en Vértice, $n^{\circ}$ 46-47, 1941.

33 ALCÁZAR, 46-47 (Madrid, 1941). Sobre esta línea argumental, previamente desarrollada, se continuaría insistiendo en escritos sobre el tema. Por ejemplo, HENRÍQUEZ, 1951. En dicha obra se apunta que los toros son PAZ, porque no significan la lucha brutal, sino el valor de un hombre bravo que se enfrenta cara a cara, y sin despreciarlo, con un noble animal que asimismo tiene que morir.

34 Ver, por ejemplo, «Sobre el valor y el miedo» y «Del valor y el dominio», ambos en ALCÁZAR, 1936.

35 ALMAGRO SAN MARTÍN, 1941. 
to. Así, por ejemplo, en 1942, se publicaba La bravura del toro de lidia, escrito por el director del Matadero de Madrid, Cesáreo Sanz Egaña, y alabado desde el madrileño $A B C$ por elevar la fiesta a «carácter científico», siendo un texto que, "pese a la picaresca» asociada con la fiesta, lograba evidenciar «una seriedad que se impone y solicita a los hombres cultivados» ${ }^{36}$. Y, un año después, el polígrafo y futuro académico, José María Cossío, comenzaba a publicar su monumental obra Los toros, cuyo primer volumen se editaba en 1943. En dicho tomo, así como en los siguientes publicados a lo largo de casi veinte años, Cossío se acercaba a la fiesta desde el más puro afán de erudición, abordando temas que comprendían desde la historia de la fiesta, pasando por aspectos técnicos del acto de torear, para llegar a las tipologías de los diferentes tipos de casta, ganaderías o hasta de ruedos. Lo especialmente significativo para la cuestión que aquí interesa no es solo la propia publicación del primer volumen sino, también, la acogida que se le dio en algunos órganos de la dictadura, en los que se señalaba la seriedad, el rigor y el docto conocimiento con los que el autor abordaba la fiesta nacional ${ }^{37}$. En definitiva, y en función de lo expuesto hasta el momento, parece plausible considerar que, efectivamente, hubo un discurso sobre los toros dirigido a dotar de seriedad y de firmeza a un espectáculo siempre susceptible de ser coloreado con los tonos propios de la paleta extranjera y que desde una exclamación hondamente nacionalista se pretendió corregir durante los años de la inmediata posguerra.

\section{La recuperación del folklore español y la restitución del flamenco}

Si, tal y como se acaba de ver, uno de los argumentos esgrimidos en la específica restitución del toreo fue la necesidad de despojar a la fiesta de todo su «artificio», según había escrito Federico M. Alcázar, algo similar ocurrió con el flamenco. Así lo recordaría muy tardíamente, y no exento de cierta abstracción lírica, Pedro Laín desde las páginas de Arbor, confesando sentir «una suerte de escalofrío íntimo» al rememorar una escena madrileña vivida en un tablao flamenco tiempo atrás. Eran ya las tres o las cuatro de la madrugada de la recordada noche cuando, habiéndose ido ya «todo el público turístico y parásito», solo quedaban ocho o diez personas en el local. El cantaor se sentía a gusto, proseguía Laín, «casi a solas consigo mismo y con el duende del cante». Y había sido en aquel momento cuando se había podido sentir la verdad del flamenco: la conciencia íntima y la lucidez del propio ser ${ }^{38}$.

$36 A B C$ (Madrid), 17 de octubre de1943, p. 38.

37 Ver, por ejemplo, la reseña que hizo Melchor Fernández Almagro en el madrileño $A B C$ del 28 de abril de 1943, p. 6, o la realizada por Rafael García Serrano en el n 66 de la revista falangista Vértice.

38 LAÍN ENTRALGO, 354 (Madrid, 1975): 168-169. 
Seguramente con menos licencia poética, pero incidiendo esencialmente en lo mismo, Celestino Espinosa - el mencionado crítico taurino de Arriba-, buceaba por el tema del cante abandonando su habitual dedicación a los ruedos para llamar la atención sobre los errores cometidos en el juicio y la opinión sobre el flamenco, intentando sentar las bases de cómo se debía entender este arte. Lo primero que había que postular es que lo flamenco, sí, era una postura típicamente española referida al conjunto de la vida, porque lo que, en última instancia, expresaba el cante era la posibilidad de encararse con el misterio interior. Había, entonces, que revalorizarlo, porque «tratar de raer lo flamenco por puros melindres y dengues, catalogándolo como espécimen de tipo inferior», era «un error indisculpable». El flamenco formaba parte del arte popular, pero no - que nadie se confundiese - de lo populachero, porque nada había tan alejado del pueblo, ni nada era, consecuentemente, más antiflamenco, que «aquel horrendo y despintado populacho» frentepopulista y chequista $^{39}$. Había sido, precisamente, debido a esta vinculación entre flamenco y los bajos fondos tan gráficamente ejemplificados en los cafés cantantes del siglo anterior por lo que buena parte de los noventayochistas y, con ellos, importantes nombres del regeneracionismo de las primeras décadas del siglo XX, habían criticado al flamenco ${ }^{40}$, siendo necesario, a partir de ese momento, acometer su rehabilitación. La finalidad era, tal y como había hecho Celestino Espinosa en el citado artículo, diferenciarlo claramente de sus falsificaciones y deformaciones, unas incorrecciones que eran consecuencia directa de los dos peligros que siempre acechaban al cante: por un lado, el escollo de la mencionada identificación entre lo flamenco y lo que el discurso de los vencedores consideraba como el populacho, un populacho que, a la sazón, aparecía políticamente identificado con el régimen anterior; por otro, su coloreamiento excesivo a tono con la romántica españolada. En ambos casos, el resultado al que se llegaba era el mismo: la ya aludida distorsión de España que finalizaba, a su vez, en la nación torcida que había que combatir.

Una posible solución para conjurar ambos peligros podía hallarse, entonces, en la insistencia en que el flamenco tenía un carácter - entendido en el mejor sentido de la palabra- popular, situado en las antípodas, tanto de su incorrección turística, como de su degradación social y cultural. Había, no obstante, que tener cuidado porque, según explicaba desde $A B C$ Francisco de Cossío, lo que comúnmente se llamaba españolada provenía de convertir en espectáculo lo genuinamente popular. Consecuentemente, lo popular perdía «su encanto, gracia y elegancia para quedar de él no más que los rasgos caricaturescos», lo que desembocaba, a su vez, en una «plebeyez» de lo que, bien tratado, habría podido ser una «obra perfecta». El flamenco corría este riesgo,

39 ESPINOSA, 30-31 (Madrid, 1940).

40 RÍOS RUIZ, 2002: 73-94. HOLGUIN (2010). 
insistía Cossío, y lo que había que subrayar era su carácter íntimo y personal, su condición de pura raza, como si el cante fuese «el depósito sagrado de una música ancestral» ${ }^{41}$.

En buena medida, esta restitución del flamenco vinculada a su popular condición se produjo gracias a las nuevas líneas ideológicas imperantes tras la guerra. Así, de acuerdo al fuerte repliegue nacionalista propio de los tiempos de victoria, se asistió en el ámbito musical a una importante exaltación y revalorización del folklore nacional, entendido este como el acervo de la tradición oral en el que latía el auténtico y altamente idealizado pueblo español ${ }^{42}$.

A pesar del uso sistemático que los regímenes dictatoriales han hecho del folklore poniéndolo al servicio de sus ideologías, el discurso oficial franquista que se desarrolló en torno a él subrayó el mantenimiento de una actitud declaradamente técnica, insistiendo en la tarea de recopilación y sistematización de las manifestaciones populares más que en las disquisiciones teóricas sobre ellas ${ }^{43}$. Así quedó manifiesto en las aulas y la academia, y así lo hizo, igualmente, a través de la iniciativa impulsada por la Sección Femenina desde finales de la guerra, una iniciativa materializada en los diversos grupos de Coros y Danzas que, a lo largo de los primeros años de posguerra, y según declaraban sus propias propulsoras, se crearon por todo el país con el fin de salvaguardar una cultura eminentemente popular, nacida en el pueblo, y en peligro de perderse u olvidarse ${ }^{44}$. Siguiendo las directrices marcadas, el afán que guiaba a estas falangistas era, tal y como ellas mismas postulaban, el de investigar y recopilar, de la mano de las Instructoras de Música colocadas al frente de los diferentes grupos, el mayor número posible de bailes y cantes ${ }^{45}$. No había, por tanto, intenciones de incidir en el tipismo o en la imagen tópica de las costumbres populares, sino de contribuir a la unidad nacional a través del profundo conocimiento del variado folklore patrio, y de aquilatar la música y la cultura españolas. Así lo explicaba años después Josefa Sampelayo, la regidora central de Cultura, cuando recordaba que el objetivo que se había marcado Pilar Primo de Rivera durante los años de la guerra había sido el de desentrañar, salvar y revitalizar lo auténticamente español para edificar sobre ello el futuro de la Patria. Ese había sido el gran acierto de la Sección Femenina, el saber ver, y el saber valorar, el tesoro inmenso y todavía recuperable

41 DE COSSÍO, FRANCISCO, «Arte de raza», $A B C$ (Madrid), 13 de febrero de 1943, p. 3.

42 PÉREZ ZULDUONDO, 2001: 93-94.

43 ORTIZ, 1999: 479-496. La autora señala que la tradición folclorística española se había basado, también, en la recopilación de material más que en la elaboración teórica al respecto. Un análisis de su génesis y consolidación, así como del papel jugado por pioneros de la disciplina como Antonio Machado Álvarez, en PRAT FERRER, 2008: 129-135.

44 «El folklore español», en Archivo Documental Nueva Andadura. Paquete 26, carpetas 1-2.

45 CASERO, 2000: cap. 5. Un ejemplo concreto de cómo se procedía en el llamado trabajo de campo, en BERLANGA, 2001: 115-134. 
del folklore. Porque no había que olvidar que, en la España de 1936, estas manifestaciones folklóricas, salvo naturales excepciones, habían prácticamente desparecido. Entre las excepciones que reconocía Sampelayo estaban Cataluña, donde lo tradicional y local habían recibido siempre un verdadero culto; Asturias y Galicia, muy apegadas, también, a sus costumbres; y, por supuesto, Andalucía, donde el cante y el baile tenían carácter espontáneo, pero donde, desafortunadamente, acechaba «siempre el peligro de la mixtificación» ${ }^{46}$.

Era para evitar este último peligro para lo que servía el trabajo de las folkloristas, para devolver su justo valor a algunos de los principales elementos con los que se había construido la imagen tópica de España. Lo dejó entrever la propia Pilar Primo de Rivera en un temprano 1939 pensando en la unidad de las tierras de España que se podría conseguir a través de la música porque, cuando los catalanes supieran cantar las canciones de Castilla, consideraba la delegada nacional; cuando en Castilla se bailasen también las sardanas y se hubiese oído hablar del chistu; cuando las canciones de Galicia llegasen hasta Levante, y cuando el cante andaluz se entendiese «en toda la profundidad y toda la filosofía que tiene, en vez de conocerlo a través de los tabladillos zarzueleros», entonces, sí, se podría hablar de la unidad entre los hombres y la tierras de España ${ }^{47}$. Consecuentemente, el trabajo de investigación, recopilación y divulgación al que se emplearon las mujeres falangistas estuvo encaminado en esta dirección. En primer lugar, había una explícita intención de ensamblar a través del arte popular a un país regionalmente plural en una férrea unidad; en segundo lugar, se ambicionaba rehabilitar el verdadero carácter del folklore español alejándolo de todo atisbo de tópico, deformación o colorida exageración; y, por último, existía, también, el empeño de difundir más allá de las propias fronteras, y según fuese avanzando la década, el patrimonio nacional, una muestra internacional del acervo patrio sin los estridentes tonos de la imagen romántica española. Como diría la misma delegada en 1948, el año en el que los Coros y las Danzas realizaban su primera salida a Argentina, la batalla del resurgimiento del folklore español se estaba ganando, ya que el mundo, en cuanto a música se refería, «no conocía España casi nada más que por una deformación de lo andaluz» ${ }^{48}$.

A dejar claro que el problema estribaba, justamente, en la deformación, se dedicaba la folklorista Nieves de Hoyos Sancho, hija del conocido antropólogo Luís de Hoyos Sainz, en un artículo sobre la crónica del concurso nacional de cantos y bailes de $1943^{49}$. Escribiendo sobre los bailes presentados por el

46 SAMPELAYO, 1969: 99-101.

47 Recogido en PRIMO DE RIVERA, 1950: 25.

48 Recogido en PRIMO DE RIVERA, 1950: 99. Un análisis general del trabajo y la función desarrollada por los Coros y Danzas, en HOLGUín (en prensa). Agradezco a la autora que me haya dejado leer un material todavía inédito.

49 Luis de Hoyos Sainz fue uno de los fundadores de la Antropología en España. De formación científica y naturalista, su primer interés recayó en la antropología física, dedicándose 
grupo de mujeres andaluzas, De Hoyos señalaba que Andalucía no había presentado nada de lo que se pudiera llamar flamenco. ¿Por qué?, se preguntaba la folklorista. «Sin duda - respondía-, porque lo flamenco muy vistoso hace tiempo que invadió los tabladillos y escenarios; aquí el arte se adulteró con vistas a un mayor atractivo, y hoy se rechaza como artículo de exportación cuando trata de buscarse lo genuinamente andaluz, sin pensar que el cante y el baile flamenco lo son en absoluto, y que lo que debe hacerse no es rechazarlos, sino depurarlos» ${ }^{50}$.

Depurar y revalorizar eran, precisamente, dos de las labores que realizaban las mujeres falangistas en su trabajo de campo. En el caso de la música de Andalucía, los informes que acompañaban a las canciones recogidas durante el trabajo de investigación resaltaban la profundidad del material encontrado en un alejamiento del alegre colorido normalmente atribuido al folklore del sur del país. A este carácter serio y melancólico, hondo y profundo, tan alejado de la panderetada, contribuía, según las folkloristas, la guitarra, uno de los instrumentos más representativos de lo andaluz. Porque, en manos de sus «hábiles ejecutantes», se obtenían de ella «apasionadores efectos: llora casi siempre, aun cuando hace bailar». No en vano, Andalucía era la tierra del cante jondo - hondo - en un nombre que ya avisaba de su profundidad ${ }^{51}$.

También sobre el efecto de la guitarra escribía Manuel García Matos, distinguido profesor ayudante desde 1941 de la Cátedra de Folklore ocupada por Nemesio Otaño en el Conservatorio de Madrid y futuro asesor de la Sección Femenina en su trabajo de Coros y Danzas, para subrayar el variado efecto que esta podía tener, un efecto que iba desde el alegre y vibrante optimismo de las alegrías, la bulería o el zapateado, hasta los lamentos y patéticos sollozos de la seguiriya, pasando por las penas y melancolías de la granaína o la taranta $^{52}$. En realidad, García Matos dedicaba parte de su autorizado conocimiento a ensalzar el flamenco, una de las manifestaciones más singulares, según su propia consideración, del riquísimo y variado folklore musical de España; tal vez el más destacado y atrayente. El problema, no obstante, era la escasa y errónea atención que este había recabado. Porque objeto, en el mejor de los casos, de la indiferencia, o en el peor, del desdén y de la más extraña incomprensión, el flamenco había conocido los más tremendo insultos, se

al estudio de las diferencias morfológicas que podían existir entre las diversas razas humanas. Posteriormente, derivó hacia un interés por la etnografía y la cultura, haciendo pioneros estudios sobre el folklore español.

50 DE HOYOS SANCHO, 69 (Madrid, 1943). La cursiva es nuestra.

51 «Breve historia de los coros y danzas. Su creación, Promoción y labor desarrollada» y «Folklore musical -Música y baile», ambos en Archivo documental Nueva Andadura, paquete 26, carpetas 1-2.

52 Recogido en GARCÍA MATOS, 1984: 129. Sobre García Matos, GÓMEZ RODRÍGUEZ, 2001: $223-226$. 
lamentaba el folklorista. En el fondo, proseguía, siempre había latido el mismo error para tan erradas interpretaciones: la creencia, «no poco generalizada, de que nada bueno, exquisito o noble puede haber en un arte que, cual el flamenco, se cría y desarrolla en malsanos ambientes y entre gentes y personas de sospechosa conducta o licenciosas costumbres». El informado artículo de García Matos se proponía, por consiguiente, situar el cante dentro del folklore andaluz, llegando, entonces, a conclusiones que incidían en su carácter profundamente popular ${ }^{53}$.

También el periodista Manuel Prados y López insistía con honda pena, según su declaración, en que uno de los principales problemas en lo que al flamenco se refería fuese su profundo desconocimiento, el hecho de que el cante y el baile del Sur no sugiriesen «en muchos casos a españoles de otras regiones sino esa incomprensión que denota prejuicio y recelo». A cambio, había que romper una lanza por la tradición artística andaluza, porque lo que el flamenco verdaderamente transmitía era elegancia, belleza, sentimiento y virtud señorial ${ }^{54}$.

De forma paralela a la academicista exaltación del folklore, la revista Rit$m o$, la principal publicación musical durante los años 40 dirigida por el jesuita Nemesio Otaño, director desde 1939 del Conservatorio de Madrid, se convirtió, del mismo modo, en una plataforma desde la que apelar a la unidad nacional y a la necesaria corrección de ciertos tópicos sobre la imagen de España. De esta manera se expresaba un editorial de septiembre de 1942, haciendo un llamamiento a la unidad para fortalecer la música patria y para evitar la desintegración de lo auténticamente español porque, tal y como se postulaba, hasta «el llamado arte flamenco» se desnaturalizaba y desvalorizaba «por la chabacanería y plebeyez» ${ }^{55}$. Quien pareció tomarse especialmente en serio esta labor fue Francisco Padín, crítico de El Diario de Cádiz y asiduo colaborador de la mencionada publicación, en sus reiteradas llamadas a que se afirmase y promoviese la música española en un momento en el que, además, se asistía a una «invasión» de música extranjera, especialmente del jazz ${ }^{56}$. Había, a cambio, que revalorizar todo lo español, pero que nadie se confundiese, proseguía el crítico, «lo español auténtico, hemos dicho; cuidado: nunca lo pintoresco de exportación, que sabe mucho a la España de pandereta» ${ }^{57}$. La advertencia, claro está,

53 GARCÍA MATOS, 1984: 13 y ss.

54 PRADOS Y LÓPEZ, Manuel, «Elogio de los cantos y bailes andaluces», $A B C, 9$ de agosto de 1944.

55 «Unidad musical», Ritmo, $\mathrm{n}^{\circ}$ 158, septiembre de 1942.

56 El discurso musical ultranacionalista en el que se demonizó al jazz como música procaz, negroide y extranjera ha sido bien estudiado. Ver, por ejemplo, IGLESIAS, 23 (Cádiz, 2010): 118-134.

57 PADÍN, 147 (Madrid, 1941). 
no era gratuita porque si la mirada foránea se había plasmado con notable éxito a través de diversos géneros literarios, también la música había sido un terreno abonado para el particular cultivo de la españolada.

A diferenciar el folklore español del pintoresquismo dedicaba el compositor Pedro Carré un artículo titulado «España y la música francesa». Para Carré, resultaba claro que la atracción que había ejercido España en los músicos franceses nada tenía que ver con el folklore patrio. No era eso lo que les atraía porque, si hubiese sido así, habrían tenido que calar hondo en las fuentes de acuerdo a la más escrupulosa etnografía y, ya se sabía: «el artista se deja ganar antes por la impresión que por el cálculo, sobre todo cuando se siente intérprete de un país extraño. Así, comprendemos por qué se abusa tanto de lo exterior para evocarnos con pintorescas pinceladas de una patria que no reconocemos sin esfuerzo» ${ }^{58}$. En una breve disertación sobre la La forza del destino, la ópera que Verdi había compuesto a partir de una obra del duque de Rivas, el compositor y musicólogo valenciano Eduardo L. Chávarri sugería que la atracción francesa por lo español se debía a su «espíritu adverso a la hispanidad», que contribuía a propagar las leyendas antiespañolas. Porque la España vista por los románticos extranjeros, singularmente por los franceses, valía «tanto como decir dos veces falsa la visión» ya que, en estos autores, había podido «más el deseo de producir efecto que no el de respetar la espiritualidad de un país ${ }^{59}$. Lo sorprendente, no obstante, era que el tópico francés sobre España todavía continuara. Así lo constataba el corresponsal de $A B C$ en París, Mariano Daranas, en la crónica que escribía sobre la cartelera de espectáculos parisina, una cartelera que ponía aún de manifiesto cómo la visión romántica de España suscitaba suficiente curiosidad en el país vecino. «El baile español, apellídese flamenco, andaluz o vagamente regional, taconea en todos los tablados, desde la Ópera al cabaret. A cada nueva semana, corresponde un cartel nuevo», corroboraba Daranas. Y es que lo que sufría la Francia del armisticio era verdaderamente «una crisis de andaluzofilia». Sin embargo, se preguntaba el corresponsal, ¿en qué se parecía «esta actividad coreográfica, con pretensiones de estética, a la danza verdadera ni al arte popular de nuestra nación?» ${ }^{60}$.

A evitar todos estos males coadyuvaban las falangistas de la Sección Femenina con su recuperación folklórica, una labor que sería altamente alabada por diferentes autoridades musicales del régimen ${ }^{61}$. Porque sería a través del

58 CARRÉ, 156 (Madrid, 1942).

59 CHÁVARRI, 147 (Madrid, 1941).

60 DARANAS, Mariano, «Del antiguo Romea a la moderna sala Pleyel», $A B C$ (Madrid), 15 de julio de 1943 , p. 8 .

${ }_{61}$ Por ejemplo, el musicólogo y crítico musical de Arriba, Federico Sopeña, calificaba en 1948 de «genial» desde las páginas de Arbor el «folklorismo vivo de la Sección Femenina». 
conocimiento del legado popular de otras regiones, escribía de nuevo Francisco Padín, como se contrarrestaría la nefasta preminencia de lo andaluz en lo que a la imagen española en danza y canto se refería, evitando, así, la tentación de que, en este caso, fueran los propios españoles los «productores» de la españolada. El problema, no obstante, estribaba en que lo considerado como andaluz, sinónimo de lo típicamente español era, en realidad:

$\mathrm{Su}$ aspecto de flamenquismo de taberna, que, a nuestro juicio, es cosa bien distinta, dicho sea en favor de esta Andalucía, erróneamente interpretada por muchos que se precian de artistas y conocedores de su alma. Bueno será que se pongan los puntos sobre las íes, en aras del nombre y prestigio del arte nacional. Que no seamos nosotros mismos los que, sin darnos cuenta, favorezcamos a esa detestable y perniciosa españolada ${ }^{62}$.

La reivindicación de la corrección del tópico andaluz le salía a Padín de su entraña gaditana. Así lo mostraba, al menos, cuando recordaba el mítico espectáculo interpretado por La Argentinita en los años 30 a partir de una versión realizada por Federico García Lorca sobre El amor brujo, de Falla, un espectáculo que se había acompañado de una interpretación de dos conocidos cuadros flamencos: Las calles de Cádiz y Nochebuena en Jerez. Para Padín, la interpretación de ambos cuadros había ejemplificado lo que ocurría cuando se trataba de exaltar «lo típicamente español»: se ofrecía a los espectadores «una muestra colorista y animada de andalucismo, pero recargada de vulgaridades y de populacherías». El problema era que, como gaditano, no podía sino producirle «enojo» el corroborar:

Que hayan contemplado los públicos españoles esta estampa de Las calles de Cádiz, donde sus tipos y sus escenas no dicen mucho en favor de nuestra tierra. Como se ve, esto del arte español, para muchos, coincide exactamente con los límites naturales de Andalucía. Las demás regiones no cuentan y, en todo caso, cuando alguna vez llevan esos conjuntos en su repertorio canciones o bailes que no son de Andalucía lo hacen ajustándose a la manera y forma de esta región (...). ¿Cuándo comprender el error? ¿Cuándo abandonar la España de la pandereta y dedicarse de lleno a la exaltación de lo auténticamente nuestro? ¿No resulta extraño que en un país donde se conocen más de un centenar de formas populares de la danza tengamos una y otra vez que asistir a la representación de lo andaluz, con influencias de flamenquismo tabernario ${ }^{63}$

Ver SOPEÑA, 36 (Madrid, 1948): 464. Un año después, en la obra escrita por el mismo Sopeña junto a Gerardo Diego y al compositor Joaquín Rodrigo, se volvían a dedicar elogiosos comentarios a la labor de la Sección Femenina. DIEGO, RODRIGO y SOPEÑA (1949): 82-83.

62 PADÍN, 153 (Madrid, 1942).

63 PADÍN, 153 (Madrid, 1942). 
Era, exactamente, debido a lo contrario, esto es, a su sobria, tradicional y clásica interpretación también de El amor brujo, por lo que, simultáneamente a la crítica de Padín, el reconocido guitarrista Regino Sainz de la Maza alababa la interpretación que de la obra de Falla estaba realizando la bailaora Pastora Imperio en el madrileño teatro Fontalba. «Siempre que Pastora baila, algo muy noble se produce en las tablas que ella pisa: porque se produce la tradición», explicaba el músico. Y es que Pastora traía a la escena toda la tradición gitana, «sin mezclas ni exotismos», para mostrar «la danza española sin mixtificaciones, el auténtico baile flamenco» ${ }^{64}$. Como se verá a continuación, si parte de lo que a lo largo de estas páginas se ha denominado el discurso de la antiespañolada se había centrado en restituir el flamenco más allá de las exageraciones o falsedades propias de una imagen deformada, otra parte de este mismo discurso se dedicaría a combatir este flamenquismo tabernario y corrompido andalucismo en el intento de devolver a Andalucía el justo carácter que le correspondía.

\section{EL DISCURSO DE LA MENTIRA: ANDALUCÍA Y LA PANDERETADA}

En un artículo publicado todavía en guerra, el poeta Joaquín Romero Murube, director, a la sazón, de los Reales Alcázares de Sevilla, se quejaba de que aún imperase sobre la ciudad «una concepción panderetesca: toros, garrochistas, dehesas, gañanes». De nuevo, el origen de esta interpretación había que buscarlo en el pasto literario del siglo XIX, cuando algunos viajeros de la talla de Dumas, Quinet o Borrow, entre otros, habían hecho su particular contribución a la construcción de «la gran Andalucía pasional: navajas, toreros, gitanas». Para Romero Murube, todo sea dicho, no había razón para oponerse al cultivo de esa literatura de ocasión que tanto había beneficiado a España desde el punto de vista de la propaganda, y que tanto había hecho reír a los lectores locales a base de disparates. Pero el peligro estribaba en pensar que en el país no había «más que pintoresquismo y sandeces afrancesadas» ${ }^{65}$.

Unos años después, Romero Murube sistematizaba sus pesares sobre su ciudad natal en un ensayo gráficamente titulado Discurso de la mentira. En él, el escritor advertía de que «la capa de falsedades y pseudo interpretaciones sevillanas» llegaba ya a ser tan compacta y tan extensa, que se corría el peligro de que aquellos que no conocían bien la ciudad creyesen que Sevilla era exclusivamente «la sede de la flamenquería trasnochada», o el «escenario de coplas de organillo», con gitanos amadamados y toreros dulces de salones

\footnotetext{
64 SAINZ DE LA MAZA, Regino, $A B C$ (Madrid) 14 de mayo de 1942, p. 20.

65 ROMERO MURUBE, 10 (Madrid, 1938).
} 
elegantes $^{66}$. Las observaciones del autor eran, en realidad, bastante certeras porque, de los diferentes paisajes y regiones del país, ninguno como Andalucía había despertado la sed de exotismo y aventura mostrada por los curiosos impertinentes que llegaban a la península durante los siglos previos. En realidad, la imagen española como primordialmente andaluza circulaba ya por Europa antes de la llegada de los románticos; no hay que olvidar, como señaló Manuel Bernal, que en la literatura de Cervantes o Quevedo muchas costumbres y personajes estaban situados en Andalucía - principalmente, en Sevilla, considerada la capital popular de España ${ }^{67}$. La imagen previa con la que muchos de los viajeros llegaban a España era, por tanto, la andaluza, una imagen que, con la oportuna subjetividad del literato dispuesto a encontrar la exótica diferencia frente a sus progresivamente industrializadas y aburguesadas ciudades, se convertiría en una estampa perdurable e influyente sobre las generaciones posteriores. Como apuntó Alberto González Troyano, el romanticismo inauguró un tipo de lectura de Andalucía de la que toda la literatura posterior se sentiría tributaria y deudora ${ }^{68}$. Pasado el tiempo, incluso regímenes políticos como la dictadura de Miguel Primo de Rivera también fomentarían, dentro de sus especificas políticas nacionalizadoras, una imagen andalu$z a$ del país, representándolo - en íntima oposición al sobrio castellanismo del fin de siglo - a través de imágenes femeninas y andaluzas, y connotando al país con la supuesta alegría propia del sur en tanto síntesis de la nación regenerada. En opinión de Alejandro Quiroga, estas políticas nacionalizadoras contribuirían, tal vez de forma no del todo consciente, a la reproducción de la imagen oriental y romántica del país ${ }^{69}$.

En cualquier caso, la culpabilidad de dicho retrato estaba clara, escribía Romero Murube: había que buscarla en los franceses e ingleses arribados al Sur y desinteresados en las disciplinas artísticas españolas o en el prestigio intelectual patrio. Ellos venían a su avío, proseguía el poeta, buscando platos fuertes para el gusto estragado de París. "A los franceses lo que les encanta, y ellos elevan al primer rango de sus producciones, son los gitanos, las majas, los toreros, los mendigos, los contrabandistas y demás comparsas. Y surge la gran españolada a base de Andalucía y, principalmente, de Sevilla». Que creyesen todo esto en el extranjero era lamentable, concluía el autor. "Allá ellos, que tienen tan hermosas tragaderas; y felices nosotros, que hemos cambiado tonterías y ñoñeces por buenas libras y buenos dólares». Lo que indignaba, sin embargo, era que esa imagen, fruto de la catetería intelectual, de la incul-

\footnotetext{
66 ROMERO MURUBE, 1943: 20-21.

67 BERNAL, 1987: 105 y ss.

68 GONZÁLEZ TROYANO, 1987.

${ }^{69}$ QUIROGA, 2007: 172.
} 
tura y del capricho romántico e interesado de los franceses, fuese tomada en serio por algunas gentes ${ }^{70}$.

«La panderetada para nosotros mismos es ya intolerable», bramaba Rome$\mathrm{ro}^{71}$. Era, consecuentemente, el momento de reivindicar esa otra Sevilla, porque era cierto que existía «una Sevilla superficial, alegre, aérea»; esa era la Sevilla cortical, visible solo por las manifestaciones más simples y llamativas. Pero había, también, otra Sevilla más auténtica; una Sevilla más profunda y más recóndita que poca gente lograba descubrir ${ }^{72}$. «¿Es posible que la gente crea que en Sevilla no hay más que cante, copitas y jaranas?», se preguntaba Romero en otro artículo algo más tardío. No se trataba de oponerse al cultivo de la alegría como algo sano y venturoso; «pero la alegría a la fuerza, el cante, la bulla, el copeo como base de todas las horas de Sevilla, es uno de los males nacidos de un sevillanismo mal entendido ${ }^{73}$. Si el sevillano tipo estaba lo más lejos posible «de la representación teatral y literaria acostumbrada», la Sevilla verdadera estaba, igualmente, «lo más lejos de la chabacanería, del estribillo pegajoso, de la vacuidad, disloque y ligereza con que ahora trasciende por los mundos $\gg{ }^{74}$. Porque había, no importaba repetirlo, dos Sevillas: una, más fácil, efectista y falsamente colorista; otra, más difícil, más seria pero, también, más desconocida y auténtica. Y ahí se hallaba el peligro: en confundir una con otra y en dejarse seducir, exclusivamente, por las estridencias de la primera.

En este punto, la crítica de la Sevilla y, por extensión, de la Andalucía de pandereta se emparentaba con un discurso paralelo que, simultáneamente $y$, en este caso, fruto del falangismo más radical, se lanzaba por esas mismas fechas contra el Madrid castizo. Los sustantivos que había elegido Romero para ilustrar a la errónea capital hispalense - chabacanería o ligereza, por ejemplo - se podían encontrar en la caracterización de ese Madrid igualmente erróneo y necesitado de corrección que se representaba en la ciudad castiza. La idea era la misma: la deformación de la rectitud del carácter de las ciudades conducía al tipismo en su versión exasperadamente alterada. El resultado era una españolería trágica y decadente, como había explicado Ramón Serrano Suñer al alcalde de Madrid en mayo de 1939; una españolería bufa, como se había apostillado desde Arriba pocos días después; en definitiva, un narcisismo de lo típico en todas sus variantes voluntariosas y caricaturescas ${ }^{75}$.

${ }^{70}$ Las citas, en ROMERO MURUBE, 1943: 23-24 y 25.

71 ROMERO MURUBE, 1943: 22.

72 ROMERO MURUBE, 1943: 50-51.

73 ROMERO MURUBE, 1995: 46.

74 ROMERO MURUBE, 1995: 38.

75 Un análisis del discurso anticasticista lanzado contra Madrid, en BOX, 27 (Madrid, 2012): 143-166. 
Si de contraponer este narcisismo típico a la seriedad y la rectitud se trataba, el periodista y crítico literario Melchor Fernández Almagro había contribuido a la tarea para el caso de su Granada natal, la ciudad que ocupaba un lugar de excepción en los relatos y las fantasías románticas, la puerta oriental fronteriza entre dos mundos, cuna de la Alhambra, del Sacromonte y de los aires moriscos ${ }^{76}$. En un artículo publicado en Patria, el órgano del partido granadino, Fernández Almagro reflexionaba sobre El último Abencerraje, la famosa novela ambientada en Granada escrita por François-René de Chateaubriand. El libro, ciertamente, era una de los frutos más destacados de las novelas románticas de viajes, plena de «resonancias» y de «bizarros colores de romance fronterizo», como escribía Fernández Almagro. El lenguaje que utilizada, no obstante, era mucho menos belicoso e indignado que el que recogería Romero Murube o el que exhibirían los falangistas en su exhortación sobre la verdad anticastiza de Madrid. Sin embargo, la idea que se expresaba en la crítica del escritor era sustancialmente idéntica: había dos Granadas, y mientras que una de ellas era la fácil, «hecha de yeso y purpurina, de moros y gitanos», la otra, por el contrario, era la Granada difícil, una Granada aún inédita, profundamente auténtica, que era preciso descubrir. ${ }^{77}$

La metáfora, como se puede comprobar, era siempre la misma. Lo había expresado un pequeño artículo de Arriba publicado a finales de mayo de 1939: el problema y el peligro de España se hallaba en que el país era un Jano con dos cabezas. Una de ellas miraba hacia el camino que conducía a la españolería grotesca; la españolería deformada, exagerada y distorsionada; la otra, hacia el sendero que arribaba a la españolería auténtica ${ }^{78}$. Una constituía la cara fácil; la otra, la cara más difícil pero, a la par, también la más verdadera. De nuevo, se entreveía el anverso y reverso de la nación en el que solo una de las dos caras existentes podía resultar válida.

Para terminar, y ante lo expuesto a este respecto, cabe concluir que, de la misma forma que el discurso franquista reformuló y reubicó semánticamente a los toros y al flamenco con el objetivo de evitar que cayesen en coloristas deformaciones propias de la mirada mixtificadora, algo muy similar ocurrió con Andalucía, escenario privilegiado, tal y como se destacó anteriormente, de la visión romántica con la que se había conformado la españolada. Lo volvió a dejar claro Melchor Fernández Almagro cuando, algún tiempo después de su artículo sobre la obra de Chateaubriand, dedicó elogiosas críticas al recién publicado Discurso de la mentira. Para el granadino, el mérito de Romero Murube estribaba en haber sabido advertir sobre los peligros que siempre

76 VIÑES MILLET, 1982: 146-194. También, GALERA ANDREU, 1992: 9-25.

77 FERNÁNDEZ ALMAGRO, Melchor, «La novela de Granada», Patria, 4 de junio de 1942. Recogido en VIÑES MILLET, 1992: 265-269.

78 R. L. M., «Decadente y castizo», Arriba, 23 de mayo de 1939. 
acechaban a la ciudad: principalmente, el «caer en la pandereta con todas sus consecuencias $\rangle^{79}$. Porque Andalucía era, escribía Fernández Almagro a propósito de otra alabanza literaria, en este caso, a las obras del anteriormente mencionado José Carlos de Luna, una tierra pintoresca como la que más, pero pintoresca «en la mejor acepción de este vocablo», ya que este «pintoresquismo no nos emocionaría si solo se expresara en el rabioso cromatismo de esta pandereta o de aquella estampa de caja de pasas» ${ }^{80}$. Y era precisamente para contribuir al restablecimiento de esta justa medida que merecía su propia tierra por lo que nombres como los de los citados Joaquín Romero Murube, Melchor Fernández Almagro o José Carlos de Luna habían levantado con indignación y pesar sus exasperadas plumas ${ }^{81}$.

\section{CONCLUSIÓN}

La historia, se apuntó al inicio de este recorrido, continuó avanzando en el tiempo para ir dejando progresivamente lejos los años de la primera posguerra. La apuesta que vino después fue igualmente mencionada al principio: incidir en el exportable pintoresquismo capaz de convertir a la nación en un destino atractivo para el turismo sucesor de aquellos primeros viajeros que se habían dejado fascinar por el exotismo de España. El propósito de este artículo, no obstante, ha sido detenerse en un discurso fabricado unos años antes de la aparición de esta postura oficial; en concreto, en lo que se ha venido denominando el discurso de la antiespañolada, dirigido explícitamente a denunciar la deformación patria que se obtenía a través del espejo mixtificador que se había iniciado tiempo atrás con la mirada romántica. En este sentido, cabe recordar la importancia que tiene la denominada «mirada del otro» en la configuración de las identidades colectivas, un proceso de formación siempre complejo en el que se dialoga y renegocia con la mirada foránea la propia asunción identitaria. En el caso que nos ocupa, los productores de este discurso fuertemente nacional fueron heterogéneos: provinieron de los diferentes sectores ideológicos del franquismo y lo difundieron a través de variados órganos de la dictadura. Fue un discurso — de ahí el interés de su estudio-

$79 A B C$ (Madrid), 26 de septiembre de 1944, p. 33.

$80 A B C$ (Madrid), 7 de agosto de 1942, p. 13.

81 Aunque no ha sido objeto de este artículo, cabe mencionar que el arabismo académico también tuvo una vertiente fuertemente conservadora que se integró en la oficialidad de la dictadura. Así, el pasado árabe de Andalucía, susceptible de ser interpretado desde la óptica orientalizante y exótica, se narró desde la hispanización de ese pasado, diferenciando la presencia árabe en España de ese otro que sería lo árabe africano. A este respecto, ver MANZANO, 2000: 23-37. 
transversal y nacido de un común y exacerbado sentimiento de nacionalismo porque lo que, en última instancia, este discurso transmitía era dolor por España; un dolor que no era nuevo en el país, sino viejo y persistente, que había sido expresado y denunciado con variable intensidad por los intelectuales de las generaciones previas a los hombres de posguerra; un dolor ya conocido que, en este caso, se volvía a reactualizar para adoptar una nueva forma.

El mencionado discurso, por tanto, existió. Sin embargo, es importante advertir que no se trata de un discurso central dentro del franquismo, sino de una idea - denunciar la imagen española que se reflejaba en la españoladaque toda una serie de actores diversos, en momentos diferentes y en función de temas y respuestas igualmente heterogéneas, lanzaron - eso sí- desde un mismo impulso nacionalista destinado a corregir lo que sentían que era una desproporción del país. No se trata, por tanto, de un discurso coherente o sistematizado, sujeto a directrices o a intenciones que hubieran sido explícitamente establecidas. Estamos, más bien, ante una respuesta relativamente espontánea que, sin embargo, y al menos durante los años aquí estudiados, se basó en argumentos más o menos similares. En este sentido, una de las ideas que se han defendido en estas páginas es que el discurso de la antiespañolada no eliminó los elementos centrales de aquella imagen que combatían, sino que apostó por su corrección y restitución, considerando que aspectos tan típicamente españoles como el flamenco, los toros o Andalucía eran, efectivamente, representativos de lo español, pero de una España que, alejada de la pandereta, se concebía recta, severa y seria.

Para terminar, es necesario concluir que reconocer y analizar el discurso de la antiespañolada producido durante los primeros años del franquismo —un discurso que parece haber pasado desapercibido para la mayoría de los historiadores que han trabajado los nacionalismos franquistas - contribuye, aunque sea sumando un aspecto colateral, a ampliar el conocimiento del vasto tema de las ideas nacionales que confluyeron dentro de la dictadura.

\section{BIBLIOGRAFÍA}

Alcázar, Federico M., Tauromaquia moderna. Primer tomo, Madrid, Sucesores de Rivadeneyra, 1936.

Alcázar, Federico M., «Sobre las competencias», Vértice, 46-47, 1941.

Almagro San Martín, Melchor, «Aristocracia y toros», Vértice, 46-47, julio-agosto de 1941.

Álvarez Barrientos, Joaquín, «Aceptación por rechazo. Sobre el punto de vista extranjero como componente del costumbrismo», en Jean-René Aymes y Serge Salaün (eds.), Le métissage culturel en Espagne, París, Presses de la Sorbonne Nouvelle, 2001, 21-36. 
Álvarez Santaló, León Carlos, «Diversión, espectáculo y corridas de toros en el siglo XVIII. Una esquina moral de la Ilustración española», Revista de Estudios Taurinos, $\mathrm{n}^{\mathrm{o}} 1$, 1994, 93-114.

Amorós, Isidro, Dos lustros de toros en la plaza Monumental de Madrid (19311941), Madrid, Gráfica Ibarra, 1942.

Andreu, Xavier, «;Cosas de España! Nación liberal y estereotipo romántico a mediados del siglo XIX», Alcores, 7, 2009, 39-61.

Andreu, Xavier, «De cómo los toros se convirtieron en fiesta nacional: los intelectuales y la cultura popular (1790-1850)», Ayer, 72(4), 2008, 27-56.

Aymes, Jean-René (comp.), Témoignages de voyageurs français, Paris, Éd. A. M. Métailié, 1983.

Berlanga, Miguel Ángel, «El uso del folklore en la Sección Femenina de Falange: el caso de Granada», en Dos décadas de cultura artística en el franquismo (19361951), Granada, Universidad de Granada, 2001, 115-134.

Bernal Rodríguez, Manuel, «Tipologías literarias de la Andalucía romántica», en Alberto González Troyano (ed.), La imagen de Andalucía en los viajeros románticos y homenaje a Gerald Brenan, Málaga, Diputación provincial, 1987, 101-124.

Bhabha, Homi K., The location of culture, Londres, Routledge, 1994.

Box, Zira, «La mirada sobre Madrid; anticasticismo y castellanismo en el discurso falangista radical de la inmediata posguerra», Historia y política, 27, 2012, 143166.

Cambria, Rosario, Los toros: tema polémico en el ensayo español del siglo XX, Madrid, Editorial Gredos, 1974.

Carré, Pedro, «España y la música francesa», Ritmo, 156, 1942.

Casero, Estrella, La España que bailó con Franco. Coros y danzas de la Sección Femenina, Madrid, Nuevas Estructuras, 2000.

Chávarri, Eduardo L., «Verdi y el sentimiento hispánico en sus óperas españolas», Ritmo, 147, 1941.

Claramunt, Fernando, República y toros (España, 1931-1939), Madrid, Egatorre, 2006.

Cossío, José María, Los toros en la poesía (Antología), Madrid, Espasa-Calpe, 1944.

De Hoyos Sancho, Nieves, «Cantos y bailes españoles», Vértice, 69, 1943.

De Urrutia, Julio, Los toros en la Guerra española, Madrid, Editora Nacional, 1974.

Diego, Gerardo; Rodrigo, Joaquín y Sopeña, Federico, Diez años de música en Espa$\tilde{n} a$, Madrid, Espasa-Calpe, 1949.

Espinosa, Celestino, «Lo flamenco», Vértice, 30-31, 1940.

Galera Andreu, Pedro, «Granada, el Oriente inmediato», en La imagen romántica de la Alhambra, Granada, Ediciones El Viso, 1992, 9-25.

García Matos, Manuel, Sobre el flamenco. Estudios y notas, Jerez, Editorial Conterco, 1984.

García Viñolas, Manuel Augusto, «Gobierno del toro», Vértice, 46-47, 1941. 
Gómez Rodríguez, José Antonio, «La etnomusicología en España, 1936-1956», en Dos décadas de cultura artística en el franquismo (1936-1951), Granada, Universidad de Granada, 2001, II; 207-258.

González Troyano, Alberto, «Los viajeros románticos y la seducción polimórfica de Andalucía», en Alberto González Troyano (ed.), La imagen de Andalucía en los viajeros románticos y homenaje a Gerald Brenan, Málaga, Diputación provincial, 1987; 11-20.

González Troyano, Alberto, El torero, héroe literario, Madrid, Espasa-Calpe, 1988.

Henríquez, José, Toros. La fiesta nacional española, Barcelona, Editorial Tipismo de España, 1951.

Holguin, Sandie, «Vergüenza y ludibrio de las ciudades modernas: los nacionalistas ante el flamenco en Barcelona, 1900-1936», paper presentado en el Seminario de Historia Contemporánea del Instituto Universitario Ortega y Gasset, 2010.

Holguin, Sandie, «Flamenco after the Civil war». Trabajo inédito.

Iglesias, Iván, «Reconstruyendo la identidad musical española: el jazz y el discurso cultural del franquismo durante la segunda Guerra Mundial», en Historia Actual on-line, 23, 2010, 118-134.

Jiménez Morales, María Isabel, «Toros y toreros en la literatura costumbrista del siglo XIX», Revista de Estudios Taurinos, 6, 1997, 43-86.

Juliá, Santos, «Anomalía, dolor y fracaso de España», Claves de Razón Práctica, 66, 1996, 10-21.

Labanyi, Jo, Lo andaluz en el cine del franquismo: los estereotipos como estrategia para manejar la contradicción, Sevilla, Fundación Centro de Estudios Andaluces, Documento de trabajo H2004/02, 2004.

Lafuente Ferrari, Enrique, «Lección y milagro de la pintura taurina», Vértice, 46-47, 1941.

Laín Entralgo, Pedro, Sobre la cultura española: confesiones de este tiempo, Madrid, Editora Nacional, 1943.

Laín Entralgo, Pedro, «La Andalucía de Pemán», Arbor, 354, 1975, 168-169.

Manzano, Carlos, «La creación de un esencialismo: la historia de Al-Andalus en la visión del arabismo español», en Fernández Parrilla, Gonzalo y Feria García, Manuel, Orientalismo, exotismo y traducción, Cuenca, Ediciones de la Universidad de Castilla la Mancha, 2000; 23-37.

Marco, Joaquín, «El costumbrismo español como reacción», en Alberto González Troyano (ed.), La imagen de Andalucía en los viajeros románticos y homenaje a Gerald Brenan, Málaga, Diputación Provincial, 1987; 125-140.

Núñez Florencio, Rafael, «Los toros», en Javier Moreno Luzón y Xosé Manoel Núñez Seixas (eds.), Ser españoles. Imaginarios nacionalistas en el siglo XX, Barcelona, RBA, 2013; 433-466.

Ortiz, Carmen, Luis de Hoyos Sainz y la antropología española, Madrid, CSIC, 1987. 
Ortiz, Carmen, «The uses of Folklore by the Franco regime», Journal of American Folklore, 446, 1999, 479-496.

Pack, Sasha, La invasión pacífica. Los turistas y la España de Franco, Madrid, Turner, 2009.

Padín, Francisco, «A propósito de una campaña en favor de la Música Española», Ritmo, 147, 1941.

Padín, Francisco, «Hacia un espectáculo nacional de canciones y bailes», Ritmo, 153, 1942.

Pérez Zulduondo, Gemma, «La música en el contexto del pensamiento artístico durante el franquismo (1936-1951)», en Dos décadas de cultura artística en el franquismo (1936-1951), Granada, Universidad de Granada, 2001; 83-104.

Prat Ferrer, Juan José, Bajo el árbol del paraíso. Historia de los estudios sobre el folclore y sus paradigmas, Madrid, CSIC, 2008.

Primo de Rivera, José Antonio, Obras, Madrid, Editorial Almena, 1971.

Primo de Rivera, Pilar, Discursos, circulares, escritos, Madrid, Gráficas Afrodisio Aguado, 1950.

Quiroga Fernández de Soto, Alejandro, Making Spaniards. Primo de Rivera and the nationalization of the masses, 1923-30, Nueva York, Palgrave McMillan, 2007.

Ríos Ruiz, Manuel, El gran libro del flamenco, vol. 1, Madrid, Calambur, 2002.

Robertson, Ian, Los curiosos impertinentes. Viajeros ingleses por España, Barcelona, Serbal, 1988.

Romero Murube, Joaquín, «El jardín de Castilleja de Guzmán», Vértice, 10, 1938.

Romero Murube, Joaquín, Discurso de la mentira, Madrid, Revista de Occidente, 1943.

Romero Murube, Joaquín, Artículos (1923-1968), Sevilla, Hermandad Sacramental de la Soledad. Parroquia de San Lorenzo, 1995.

Sampelayo, Josefa, «Labor de la Sección Femenina en el resurgimiento del folklore español», en Etnología y tradiciones populares, Zaragoza, Institución Fernando el Católico, 1969, 99-101.

Saz, Ismael (ed.), España: la mirada del otro, monográfico de la revista Ayer, 31, 1998.

Saz, Ismael, España contra España. Los nacionalismos franquistas, Madrid, Marcial Pons, 2003.

Serrano, María del Mar, «Viajes y viajeros por la España del siglo XIX», en Geo Crítica. Cuadernos críticos de Geografía Humana, 88, 1993.

Shubert, Adrian, Death and Money in the afternoon, Nueva York, Oxford University Press, 1999.

Sopeña, Federico, «La música en la generación del 98», en Arbor, 36, 1948; 459-464.

Storm, Eric, «Una España más española. La influencia del turismo en la imagen nacional», en Javier Moreno Luzón y Xosé Manoel Núñez Seixas (eds.), Ser españoles. Imaginarios nacionalistas en el siglo XX, Barcelona, RBA, 2013, 530-559.

Tovar, Antonio, El Imperio de España, Madrid, Afrodisio Aguado, 1941. 
Viñes Millet, Cristina, Granada en los libros de viajes, Granada, Miguel Sánchez Editor, 1982.

Viñes Millet, Cristina, La Granada de Melchor Fernández Almagro. Antología, Granada, Universidad de Granada, 1992.

Recibido: 22/01/2013

Aceptado: 03/10/2013 